\title{
Protocol for awake prone positioning in COVID-19 patients: to do it earlier, easier, and longer
}

\author{
Guy Bower ${ }^{1}$ and Hangyong $\mathrm{He}^{2^{*}}$ (D)
}

Dear editor,

We read with great interest the brief report by $\mathrm{Xu}$ and colleagues [1] about the effects of early awake prone positioning (PP) combined with high-flow nasal cannula (HFNC) in ten coronavirus disease 2019 (COVID-19) patients. However, some details in the use of PP in nonintubated patients with COVID-19 need to be further clarified based on recently published data.

First, which criteria should we use to identify appropriate candidates for awake PP in COVID-19? Xu et al. used PFR $<300 \mathrm{mmHg}$ as their only criteria. Other studies have not used blood gas analysis. A study of 50 COVID-19 patients treated with awake PP used $\mathrm{SpO}_{2}<93 \%$ despite supplemental oxygen (rather than PFR) as an indication to trial PP [2]. Replacing PFR with $\mathrm{SpO}_{2} / \mathrm{FiO}_{2}$ (and removing the need for PEEP) may allow COVID-19-related ARDS to be diagnosed in patients on HFNC or face-mask oxygen without the need for NIV or blood gases. This may have advantages in healthcare facilities with more limited resources. We suggest considering awake PP in patients with $\mathrm{SpO}_{2}>94 \%$ requiring either $0.3-0.6 \mathrm{FiO}_{2}$ (with HFNC or NIV) or an oxygen flow rate of $2-10 \mathrm{~L} / \mathrm{min}$ (with a face-mask or nasal cannulae). These oxygen requirements correspond to an $\mathrm{SpO}_{2} / \mathrm{FiO}_{2}$ range of $140-$
315 which approximates a PFR $100-300 \mathrm{mmHg}$, indicating mild to moderate ARDS $[1,2]$.

Second, what is the optimal duration of awake PP? In the report by $\mathrm{Xu}$ et al. [1], the target time of PP was more than $16 \mathrm{~h}$ per day. However, the actual duration was not reported. In a study for intubated COVID-19 patients, prolonged PP of $36 \mathrm{~h}$ was associated with better PFR improvement and this was maintained after supine positioning [3]. Therefore, although a duration of $2-3 \mathrm{~h}$ of PP is tolerable for awake COVID-19 patients $[4,5]$, a pragmatic approach which allows patients to lie prone as long as they feel comfortable seems reasonable $[1,4]$.

Finally, how should we monitor for failure of awake PP and avoid delay in intubation? Xu et al. [1] do not describe the use of any exclusion criteria when considering awake PP. Patients should be monitored with pulse oximetry for $30 \mathrm{~min}$ following awake PP as $\mathrm{SpO}_{2}$ may fall temporarily and a judgement must be made whether to continue. A sustained $\mathrm{PFR}<100$ $\mathrm{mmHg}$ or $\mathrm{SFR}<140 \mathrm{mmHg}$ after PP may indicate need for intubation $[2,4,5]$.

In summary, a protocol for an early recognition and better monitoring of awake PP in this population is proposed in Fig. 1.
This comment refers to the article available at https://doi.org/10.1186/ s13054-020-02991-7.

* Correspondence: yonghang2004@sina.com

${ }^{2}$ Department of Respiratory and Critical Care Medicine, Beijing Institute of Respiratory Medicine, Beijing Chao-Yang Hospital, Capital Medical University, No. 8 Gongren Tiyuchang Nanlu, Chaoyang District, Beijing 100020, China Full list of author information is available at the end of the article (c) The Author(s). 2020 Open Access This article is licensed under a Creative Commons Attribution 4.0 International License, which permits use, sharing, adaptation, distribution and reproduction in any medium or format, as long as you give appropriate credit to the original author(s) and the source, provide a link to the Creative Commons licence, and indicate if changes were made. The images or other third party material in this article are included in the article's Creative Commons licence, unless indicated otherwise in a credit line to the material. If material is not included in the article's Creative Commons licence and your intended use is not permitted by statutory regulation or exceeds the permitted use, you will need to obtain permission directly from the copyright holder. To view a copy of this licence, visit http://creativecommons.org/licenses/by/4.0/ The Creative Commons Public Domain Dedication waiver (http://creativecommons.org/publicdomain/zero/1.0/) applies to the data made available in this article, unless otherwise stated in a credit line to the data. 


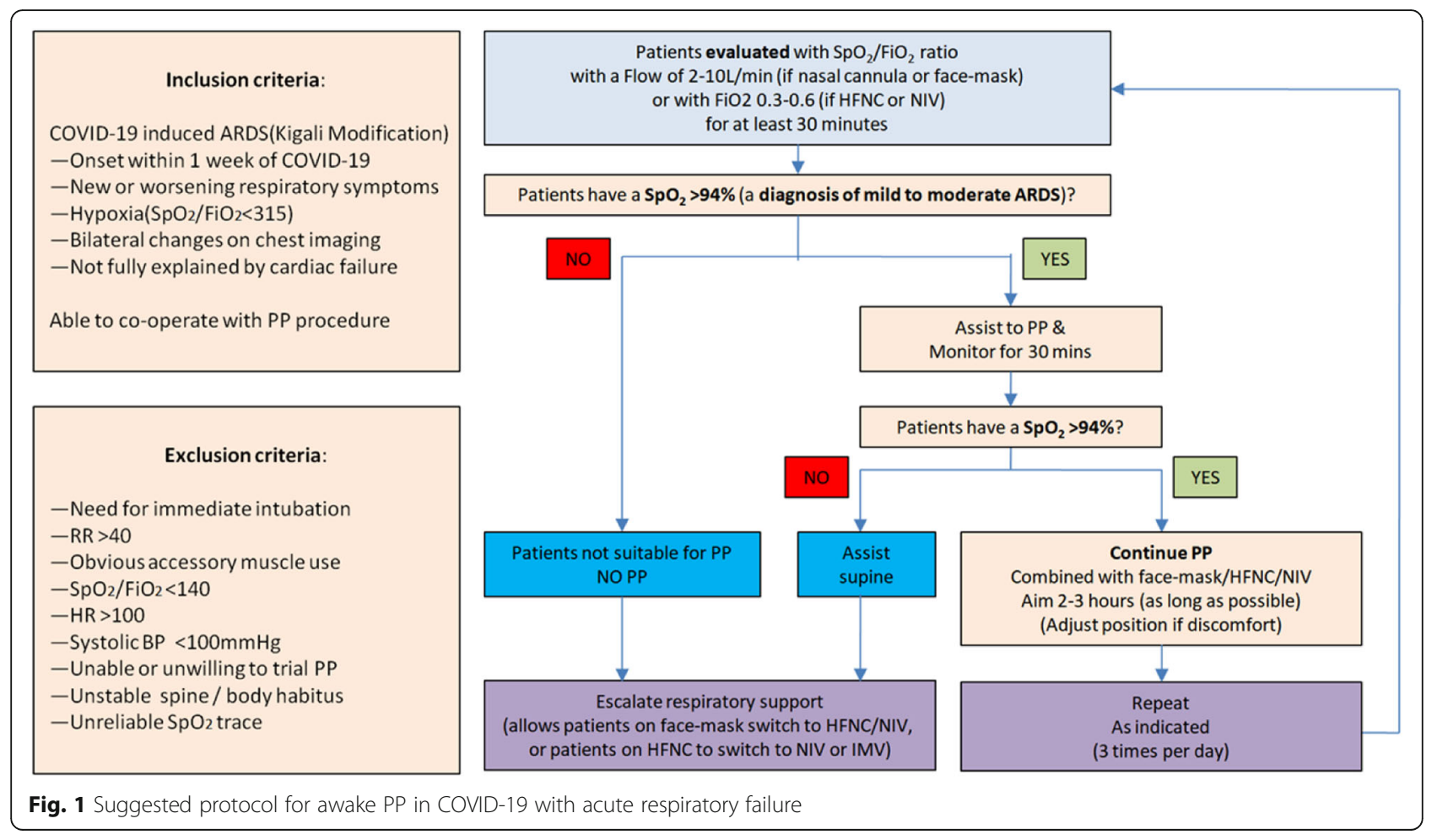

\section{Authors' response}

Qiancheng $\mathrm{Xu}^{\mathrm{a}}$, Weihua $\mathrm{Lu}^{\mathrm{a}}$

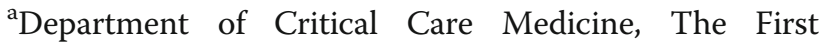
Affiliated Hospital of Wannan Medical College (Yijishan Hospital of Wannan Medical College), No.2, West road of Zheshan, Jinghu District, Wuhu, Anhui, 241000, China

Dear editor,

We would like to thank Dr. Bower for their insightful comments on our paper recently published in Critical Care [1]. Studies have shown that $78 \%$ of coronavirus disease 2019 (COVID-19) patients exhibit hypoxaemia and that $32 \%$ of patients need ventilation due to acute respiratory failure [6]. Prone position (PP) ventilation is usually used as a salvage treatment for COVID-19 in critical cases. In our study, awake PP was applied early to reduce the requirement for respiratory support, tracheal intubation rate, and progression to a critical situation.

In clinical cases, many patients with respiratory failure/hypoxaemia do not present symptoms of dyspnoea (silent hypoxaemia), especially elderly patients [7], and their $\mathrm{SpO}_{2}$ is greatly affected by $\mathrm{FiO}_{2}$. Therefore, PP may be delayed if $\mathrm{SpO}_{2}$ and $\mathrm{RR}$ are used as criteria. In our study, a $\mathrm{P} / \mathrm{F}$ ratio $\leq 300 \mathrm{mmHg}$ was used as the only criterion, whereas $\mathrm{SpO}_{2}$ and respiratory rate were used as reference indicators. We also agree with Dr. Bower's view that this approach may require additional resources.

For the timing of conversion to invasive ventilation, since the therapy is applied to avoid organ damage secondary to hypoxaemia, we focused on $\mathrm{SpO}_{2}$ as the target of oxygen therapy rather than the $\mathrm{P} / \mathrm{F}$ ratio, which reflects the degree of lung injury. There was a patient with a $\mathrm{P} / \mathrm{F}$ ratio $\leq 100 \mathrm{mmHg}$ who avoided intubation in our study. Siemieniuk et al. [8] recommended that a target $\mathrm{SpO}_{2}$ range of $90-94 \%$ seems reasonable for most patients. A previous programme proposed a COVID-19 $\mathrm{SpO}_{2}$ maintenance target in non-pregnant adult patients $\geq 90 \%$ and $92-95 \%$ for pregnant patients [9]. In our research, we changed the criteria to invasive mechanical ventilation for a patient with $\mathrm{SpO}_{2}$ less than or equal to $90 \%$ at an $\mathrm{FiO}_{2}$ of $100 \%$ for at least 5 min or $\mathrm{SpO}_{2}>90 \%$ but with high respiratory load, respiratory acidosis, haemodynamic instability, multiple organ dysfunction, and mental disorders.

The specific duration of the PP should be determined with consideration of the local medical resources and the patient's condition. Each of our treatment units consisted of a nurse, a respiratory therapist, and a 
psychotherapist, so they could closely monitor conditions that can prolong the prone position. However, there were difficulties in healthcare facilities without sufficient staff.

Finally, comprehensive treatment of COVID-19 may be more important. Our treatments could include convalescent plasma, tocilizumab, and anticoagulant therapy to reduce the duration of virus replication and respiratory support. Therefore, early awake PP can effectively prevent hypoxaemia in patients with severe COVID-19.

\section{Abbreviations}

COVID-19: Coronavirus disease 2019; PP: Prone position; $\mathrm{SpO}_{2}$ : Peripheral blood oxygen saturation; $\mathrm{FiO}_{2}$ : Fraction of inspired oxygen

\section{Acknowledgements}

None.

\section{Authors' contributions}

$\mathrm{GB}$ and $\mathrm{HH}$ are responsible for study design and writing, and this manuscript is approved by $\mathrm{HH}$. The authors read and approved the final manuscript.

\section{Funding}

None.

Availability of data and materials

Not applicable.

Ethics approval and consent to participate

Not applicable.

\section{Consent for publication}

Not applicable.

\section{Competing interests}

The authors declare that they have no competing interests.

\section{Author details}

'St George's University Hospitals NHS Foundation Trust, London, UK. ${ }^{2}$ Department of Respiratory and Critical Care Medicine, Beijing Institute of Respiratory Medicine, Beijing Chao-Yang Hospital, Capital Medical University, No. 8 Gongren Tiyuchang Nanlu, Chaoyang District, Beijing 100020, China.

Received: 2 June 2020 Accepted: 15 June 2020

Published online: 23 June 2020

\section{References}

1. Xu Q, Wang T, Qin X, Jie Y, Zha L, Lu W. Early awake prone position combined with high-flow nasal oxygen therapy in severe COVID-19: a case series. Crit Care. 2020;24(1):250.

2. Ding $L$, Wang $L, M a W$, He H. Efficacy and safety of early prone positioning combined with HFNC or NIV in moderate to severe ARDS: a multi-center prospective cohort study. Crit Care. 2020;24(1):28.

3. Carsetti A, Damia Paciarini A, Marini B, Pantanetti S, Adrario E, Donati A Prolonged prone position ventilation for SARS-CoV-2 patients is feasible and effective. Crit Care. 2020;24(1):225.

4. Caputo ND, Strayer RJ, Levitan R. Early self-proning in awake, non-intubated patients in the emergency department: a single ED's experience during the COVID-19 pandemic. Acad Emerg Med. 2020;27(5):375-8.

5. Sartini C, Tresoldi M, Scarpellini P, Tettamanti A, Carco F, Landoni G, Zangrillo A. Respiratory parameters in patients with COVID-19 after using noninvasive ventilation in the prone position outside the intensive care unit. JAMA. 2020;323(22):2338-40

6. Huang C, Wang Y, Li X, Ren L, Zhao J, Hu Y, Zhang L, Fan G, Xu J, Gu X, et al. Clinical features of patients infected with 2019 novel coronavirus in Wuhan, China. Lancet. 2020;395(10223):497-506.
7. Xie J, Tong Z, Guan X, Du B, Qiu H, Slutsky AS. Critical care crisis and some recommendations during the COVID-19 epidemic in China. Intensive Care Med. 2020;46(5):837-40.

8. Siemieniuk R, Chu DK, Kim LH, Guell-Rous MR, Alhazzani W, Soccal PM, Karanicolas PJ, Farhoumand PD, Siemieniuk J, Satia I, et al. Oxygen therapy for acutely ill medical patients: a clinical practice guideline. BMJ. 2018;363: k4169.

9. [Diagnosis and clinical management of 2019 Novel coronavirus infection: an operational recommendation of Peking Union Medical College Hospital (V2.0)]. Zhonghua Nei Ke Za Zhi 2020, 59(3):186-8.

\section{Publisher's Note}

Springer Nature remains neutral with regard to jurisdictional claims in published maps and institutional affiliations. 